\title{
mPGES-1-Derived PGE 2 Contributes to Indoxyl Sulfate-Induced Mesangial Cell Proliferation
}

\author{
Shuzhen Li $i^{a, b, c}$ Zhenzhen Sun ${ }^{a, b, c}$ Guixia Ding ${ }^{a, b, c}$ Wei Gong ${ }^{a, b, c}$ Jing Yu $u^{a, b, c}$ \\ Weiwei Xiaa,b,c Songming Huanga, ${ }^{a, b, c}$ Aihua Zhang ${ }^{a, b, c}$ Yue Zhang ${ }^{a, b, c}$ \\ Zhanjun Jia $a^{a, b, c}$
}

aDepartment of Nephrology, Children's Hospital of Nanjing Medical University, Nanjing, '⿳N口anjing Key Laboratory of Pediatrics, Children's Hospital of Nanjing Medical University, Nanjing, c Jiangsu Key Laboratory of Pediatrics, Nanjing Medical University, Nanjing, China

\section{Key Words}

Indoxyl sulfate $\cdot$ MPGES- $1 \cdot \mathrm{PGE}_{2} \cdot$ Mesangial cells $\bullet$ Proliferation

\begin{abstract}
Background/Aims: We previously reported that indoxyl sulfate (IS) could cause mesangial cell (MC) proliferation via a cyclooxygenase (COX)-2-dependent mechanism. However, the specific prostaglandin contributing to COX-2 effect on IS-induced MC proliferation remained unknown. Thus, the present study was undertaken to examine the role of microsomal prostaglandin E synthase-1 (mPGES-1)-derived Prostaglandin E2 $\left(\mathrm{PGE}_{2}\right)$ in IS-induced MC proliferation. Methods: IS was administered to the MCs with or without mPGES-1 siRNA pretreatment to induce the MC proliferation which was determined by cell cycle analysis, DNA synthesis, and the expressions of cyclins. In another experimental setting, $\mathrm{PGE}_{2}$ was applied to the MCs to examine its direct effect on MC proliferation, as well as the regulation of prostaglandin E receptors (EPs) by qRT-PCR. Results: With the administration of IS, MPGES1 (not mPGES-2 and cytosolic PGES) was significantly upregulated at both protein and mRNA levels in line with a promoted MC proliferation. Interestingly, silencing mPGES-1 reduced cell number in S and G2 phases and blocked the upregulation of cyclin A2 and cyclin D1 in parallel with blunted $\mathrm{PGE}_{2}$ release after IS treatment, indicating that $\mathrm{mPGES}$-1-derived $\mathrm{PGE}_{2}$ could contribute to $\mathrm{MC}$ proliferation. Furthermore, we confirmed that exogenous $\mathrm{PGE}_{2}$ could directly trigger the proliferative response in MCs. Lastly, we observed a selective upregulation of EP2 after PGE2 treatment and enhanced phosphorylation of NF-KB following IS administration in $M C s$, suggesting the potential involvements of EP2 and NF-KB in this pathological process. Conclusion: $\mathrm{mPGES}$-1-derived $\mathrm{PGE}_{2}$ contributed to IS-induced mesangial cell proliferation.
\end{abstract}




\section{Cellular Physiology Cell Physiol Biochem 2017;43:271-281

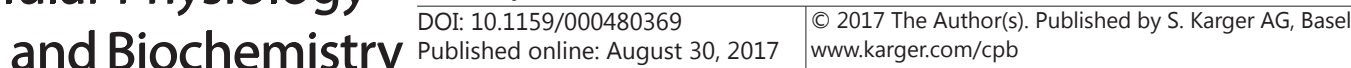 \\ Li et al.: $\mathrm{mPGES}$-1-Derived $\mathrm{PGE}_{2}$ and is-Induced Mesangial Cell Proliferation}

\section{Introduction}

In end stage renal disease (ESRD) patients, residual kidney function (RKF) is associated with the status of nutrition, inflammation, cardiac hypertrophy, and life quality [1-4]. Besides helping to maintain the fluid balance, RKF is also important in removing the plasma solutes that could not be effectively cleared by the dialysis. In general, the clearance of middle to large molecular weight uremic toxins such as indoxyl sulfate more relies on the renal metabolism and tubular secretion $[4,5]$. Therefore, loss of RKF not only indicates a progressive reduction of glomerular filtration rate (GFR) and loss of functional nephrons, but also results in more serious uremia in ESRD patients.

IS is a product of indole metabolism in the liver and is mainly excreted from the kidney [6]. However, IS cannot be efficiently removed by conventional hemodialysis because of its high binding affinity to albumin [7]. Inadequate clearance of IS leads to its accumulation in circulation, which may promote the glomerular injury of residual nephrons, leading to a faster loss of RKF [8-11]. In agreement with this notion, IS was shown to trigger mesangial cell (MC) proliferation and extracellular matrix deposition [12, 13]. As a type of native glomerular cells, MCs are very sensitive to various insults [14-18]. In a number of primary and secondary glomerular diseases, MC proliferation and subsequent glomerular sclerosis are dominant pathological features $[19,20]$.Therefore, it is worthwhile to better understand the IS effects on MC damage, as well as the underlying mechanisms.

As a major product of arachidonic acid (AA) metabolism, $\mathrm{PGE}_{2}$, has been shown to have multiple biological actions in modulating the glomerular filtration, renin release, and cell proliferation in kidney [21]. COX-1 and COX-2 chiefly regulate the production of five major prostaglandins $\left(\mathrm{PGE}_{2}, \mathrm{PGI}_{2}, \mathrm{PGD}_{2}, \mathrm{PGF}_{2 \alpha^{\prime}}\right.$ and TXA2) by supplying the substrate $\left(\mathrm{PGH}_{2}\right)$ to the prostaglandin synthetic enzymes including mPGES-1 [22]. Our previous study showed that IS significantly increased the COX-2 (not COX-1) expression to promote MC proliferation [13]. However, it still needs evidence to define the specific prostaglandin in mediating COX-2 effect on promoting MC proliferation. As a specific enzymatic source of $\mathrm{PGE}_{2}, \mathrm{mPGES}-1$ has been reported to participate in the pathogenesis of multiple renal diseases [23, 24]. Therefore, we speculated that $\mathrm{mPGES}$-1-derived $\mathrm{PGE}_{2}$ might be involved in the MC proliferation induced by IS.

\section{Materials and Methods}

\section{Materials}

Indoxyl Sulfate and $\mathrm{PGE}_{2}$ were purchased from Sigma (St. Louis, MO). Dulbecco's modified Eagle's medium (DMEM), fetal bovine serum (FBS), penicillin-streptomycin, and trypsin-EDTA solution were purchased from Gibco (Invitrogen, Grand Island, NY). Cyclin D1 mouse monoclonal antibody and cyclin A2 rabbit polyclonal antibody were purchased from Abcam. mPGES-1 mouse monoclonal antibody was purchased from Cayman Chemicals (Ann Arbor, MI). Anti-GAPDH (catalog no. ab9485) and anti-p-NFkB (catalog no. 3031S) were bought from Cell Signaling Technology (Danvers, MA). The PGE ${ }_{2}$ enzyme immunoassay kit was from Cayman Chemicals (Ann Arbor, MI).

\section{MC culture and siRNA transfection}

The mouse MC line (SV40 MES 13) was obtained from the China Center for Type Culture Collection (CCTCC Wuhan, China). Cells were maintained at $37^{\circ} \mathrm{C}$ in a humidified $5 \% \mathrm{CO}_{2}$ atmosphere in DMEM which contained $5.6 \mathrm{mM}$ glucose, 10\% fetal bovine serum (FBS, GIBCO), $100 \mathrm{U} / \mathrm{ml}$ penicillin $100 \mathrm{mg} / \mathrm{ml}$ streptomycin, $44 \mathrm{mM} \mathrm{NaHCO}_{3}$, and $14 \mathrm{mM}$ 4-(2-hydroxy-ethyl)-1-piperazineethanesulfonic acid. After 2 or 3 days, cells were digested with $0.25 \%$ trypsin and $0.02 \%$ EDTA, and seeded at a density of $3 \times 10^{4} / \mathrm{ml}$ in 6-well plates for experiment. siRNAs for mPGES-1 and the silencer negative control were bought from Gene Pharma (Shanghai, China). mPGES-1 siRNA consisted of an RNA duplex containing a sense strand: 5'-GCACACUGCUGGUCAUCAATT-3' and an antisense strand: 5'-UUGAUGACCAGCAGUGUGCTT-3'. Cells were transfected with siRNA using the Lip2000 Kit (Invitrogen, Carlsbad, CA) $24 \mathrm{~h}$ before the experiments were initiated according to the manufacturer's instructions.

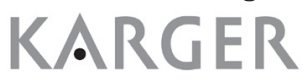




\section{Cellular Physiology Cell Physiol Biochem 2017;43:271-281 \begin{tabular}{l|l|l} 
and Biochemistry Published onlıne: August 30, 2017 & $\begin{array}{l}\text { (c) } 2017 \text { The Author(s). Published by S. Karger AG, Basel } \\
\text { www.karger.com/cpb }\end{array}$
\end{tabular}}

Determination of DNA synthesis

The thymidine incorporation assay was used to detect mesangial cell proliferation. After the centrifugation, cell pellets were resuspended into the DMEM with 1\% FBS, and then placed in 96-well plates. Following the indicated treatments, cells were incubated with $\left[{ }^{3} \mathrm{H}\right]$-thymidine $(5 \mu \mathrm{Ci} / \mathrm{ml})$, and then were harvested and incubated at $4^{\circ} \mathrm{C}$ with trichloroacetic acid (5\%) followed by solubilization in $0.1 \mathrm{~N} \mathrm{NaOH}$. Radioactivity was determined by scintillation counting.

Cell cycle analysis

Cell cycle analysis was performed by flow cytometry as previously described [25]. MCs were induced with the indicated agents for $24 \mathrm{~h}$. Cells were washed with PBS before digested with $0.25 \%$ trypsin and fixed in $70 \%$ ethanol for at least $2 \mathrm{~h}$ at $4^{\circ} \mathrm{C}$. Permeated cells were collected by centrifugation, and then treated with RNase, stained with propidium iodide by using cell cycle detection kit (KeyGEN, Shanghai, China). The number of cells in G1, S, and G2/M cell cycle phases was analyzed by flow cytometry using a BD FACS Calibur flow cytometer (Bedford, MA), and data analysis was performed with modifit3.0 software.

\section{Quantitative real-time PCR ( $q R T-P C R)$}

Total RNA was extracted from cultured MCs by using a Trizol reagent (TaKaRa) according to the manufacturer's protocol. cDNA was synthesized using a PrimeScript RT reagent Kit (TaKaRa) according to the manufacturer's protocol. The reactions were incubated at $37^{\circ} \mathrm{C}$ for $15 \mathrm{~min}$ and then at $85^{\circ} \mathrm{C}$ for 5 sec. cDNA amplification was performed using the ABI 7500 Real-Time PCR Detection System (Foster City, CA) and SYBR Premix Ex Taq (TaKaRa). Oligonucleotides were designed using Primer5 software (available at http://frodo.wi.mit.edu/) and the sequences are shown in Table 1 . The cycling program consisted of a preliminary denaturation $\left(95^{\circ} \mathrm{C}\right.$ for $\left.10 \mathrm{~min}\right)$, followed by 40 cycles $\left(95^{\circ} \mathrm{C}\right.$ for $15 \mathrm{~s}$ and $60^{\circ} \mathrm{C}$ for $1 \mathrm{~min}$ ). Relative gene expression of mRNA was normalized to GAPDH and calculated using the $\Delta \Delta \mathrm{Ct}$ method (where Ct is threshold cycle).

\section{Western blotting analysis}

After the treatment, MCs were rapidly washed with ice-cold PBS and lysed on ice using lysis buffer containing protease inhibitors. Protein concentration was determined using a Micro BCA protein assay kit with bovine serum albumin as a standard (Pierce, Thermo). Then 60 ug protein was separated by SDSPAGE and transferred onto PVDF membrane. The membranes were blocked by TBS-T $0.1 \%$ Tween 20 in TBS) containing 5\% nonfat milk for $1 \mathrm{~h}$ at room temperature, and then incubated with primary antibodies against cyclin D1 (1:1000), cyclin A2 (1:500), p-NF- $\kappa B$, and mPGES-1 (1:500) overnight at $4^{\circ} \mathrm{C}$, followed by the incubation of HRP-labeled secondary antibodies at room temperature for $1 \mathrm{~h}$. GAPDH was used as an internal control. Membranes were visualized by chemiluminescence reaction. Band intensity was quantified using Image J software (NIH, Bethesda, Table1. Sequences of primers for quantitative real-time PCR MD, USA).

\section{Enzyme immunoassay}

Cell culture medium was centrifuged for $5 \mathrm{~min}$ at 12, $000 \mathrm{~g}$ and the supernatant was collected for $\mathrm{PGE}_{2}$ analysis. The concentration of $\mathrm{PGE}_{2}$ in the cell culture medium was determined by enzyme immunoassay kit (Cayman Chemical) according to the manufacturers' instructions.

\section{Data analysis}

\begin{tabular}{lcc}
\hline Gene symbol & Primer Sequence & Accession Number \\
\hline cyclin D1 & 5'-CGCCCTCCGTTTCTTACTTC-3' & NM_007631.2 \\
& 5'-GCAGTCAGGGGAATGGTCT-3 & \\
cyclin A2 & 5'-AAGATGCCCTGGCTTTTAGTG-3' & NM_009828.2 \\
& 5'-TAACATTCACTGGCTTTTCGTCT-3 & \\
mPGES-1 & 5'-AGCACACTGCTGGTCATCAA-3' & BC024960 \\
& 5'-CTCCACATCTGGGTCACTCC-3' & \\
mPGES-2 & 5'-GCTGGGGCTGTACCACAC-3' & NM_133783 \\
& 5'-GATTCACCTCCACCACCTGA-3' & \\
cPGES & 5'-GGTAGAGACCGCCGGAGT-3' & NM_019766 \\
& 5'-TCGTACCACTTTGCAGAAGCA-3' & \\
EP1 & 5'-CAGTGAAGTGCGGGTGGAG-3' & NM_013641.2 \\
& 5'-TATTGGGGAGCCTGGGTGT-3' & \\
EP2 & 5'-ATGCTCCTGCTGCTTATCGT-3' & NM_008964.4 \\
& 5'-TATGGCGAAGGTGATGGTC-3' & \\
EP3 & 5'-GTGTGTGCTGTCCGTCTGTT-3' & NM_011196.2 \\
& 5'-TCCTTCTCCTTTCCCATCTGT-3' & \\
EP4 & 5'- TCTTACTCATCGCCACCTCTC-3' & NM_001136079.2 \\
& 5'-TGGGGTTCACAGAAGCAATC-3' & \\
GAPDH & 5'-GTCTTCACTACCATGGAGAAGG-3' & M32599 \\
& 5'-TCATGGATGACCTTGGCCAG-3' & \\
\hline
\end{tabular}

SD. Statistical analysis was performed using ANOVA analysis followed by a Bonferroni posttest. $P<0.05$ was considered statistically significant. 


\section{Cellular Physiology

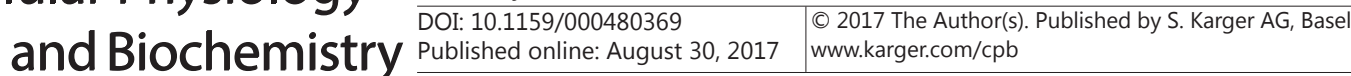

\section{Results}

\section{IS treatment enhanced mPGES-1expression in MCs}

In order to verify the hypothesis that PGE ${ }_{2}$ derived from mPGES-1contributes to the mesangial cell proliferation induced by IS, we measured the expressions of mPGES-1, mPGES-2, and cytosolic PGES (cPGES) and found that IS enhanced mPGES-1 while decreased mPGES-2 at mRNA levels in dose- and time-dependent manners (Fig. 1A-D). However, cPGES only showed a trend reduction (Fig. 1E-F). We further detected the mPGES-1 protein expression using Western blotting. As shown in Fig. 1G\&H, mPGES-1 protein was significantly upregulated following IS treatment $(500 \mu \mathrm{M})$. These data suggested that IS could directly and selectively upregulate mPGES-1 expression in MCs.

Silencing $m P G E S$-1ameliorated MC proliferation and PGE $E_{2}$ production induced by IS in MCS

As an inducible enzyme for $\mathrm{PGE}_{2}$ production, mPGES-1 is of importance in the pathogenesis of a number of inflammatory diseases. To define its contribution in IS-induced MC proliferation, MCs were transfected with mPGES-1 siRNA prior to the IS treatment (Fig. $2 A \& B)$. Then we found that mPGES-1 upregulation was strikingly blocked in line with a significant blockade of $\mathrm{PGE}_{2}$ secretion in the medium following IS treatment (Fig. 2C-F). Notably, DNA synthesis analysis showed that mPGES-1 silencing significantly reduced the amount of $\left[{ }^{3} \mathrm{H}\right]$ thymidine incorporated into the newly synthesized DNA after IS treatment (Fig. 2G), suggesting an amelioration of MC proliferation. Furthermore, the flow cytometry analysis demonstrated that the cell cycle progression was also blocked as shown by the

Fig. 1. Effects of IS on the expressions of prostaglandin E synthetic enzymes in MCs. After MCs were treated with IS, mPGES-1, mPGES-2, and cPGES levels were examined following IS treatment. (A) qRTPCR analysis of mPGES- 1 in a dose-dependent experiment. (B) qRT-PCR analysis of $\mathrm{mPG}$ ES-1 in a time course study. (C) qRT-PCR analysis of mPGES-2 in a dose-dependent experiment. (D) qRT-PCR analysis of mPGES-2 in a time course study. (E) qRT-PCR analysis of cPGES in a dose-dependent experiment. (F) qRT-PCR analysis of cPGES in a time course study. (G) Representative images of Western blots of $\mathrm{mPG}$ ES-1 following IS treatment in a time-course study. $(\mathrm{H})$ Quantitative analysis of mPGES-1 in G. All values are means $\pm S D ; n$ $=6$ in each group. ${ }^{*} \mathrm{P}<0.05$ vs. control, ${ }^{* *} \mathrm{P}<0.01$ vs. control.

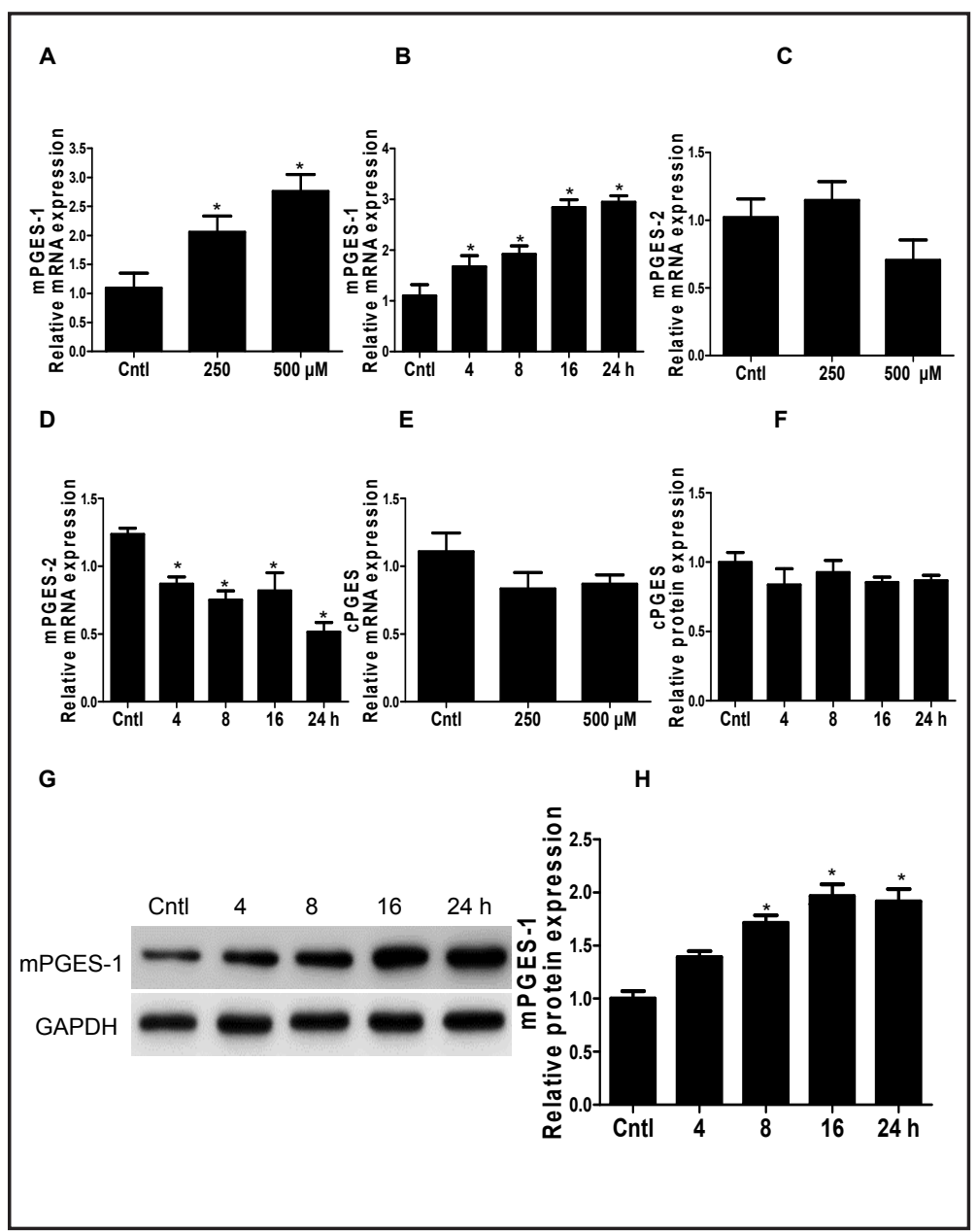


reduced percentage of cells in $\mathrm{S}$ and G2/S phases and increased cell population in G1/G0 phase after silencing mPGES-1 (Fig. 3A-H). These data demonstrated that mPGES-1 was important in promoting the cell cycle progression in MCs.

\section{Silencing mPGES-1 blocked IS-induced cyclin expression}

It is known that the progression of cell cycle is mainly regulated by cyclins in mammalian cells. Thus, we examined cyclin A2 and cyclin D1 levels in IS-treated MCs with or without mPGES-1 silencing. As shown in Fig. 4A-D, the upregulation of cyclin A2 and cyclin D1 induced by IS was significantly blunted by silencing mPGES-1 at both mRNA and protein levels. These data further confirmed that mPGES-1 is of importance in mediating IS-induced cell cycle progression in MCs.

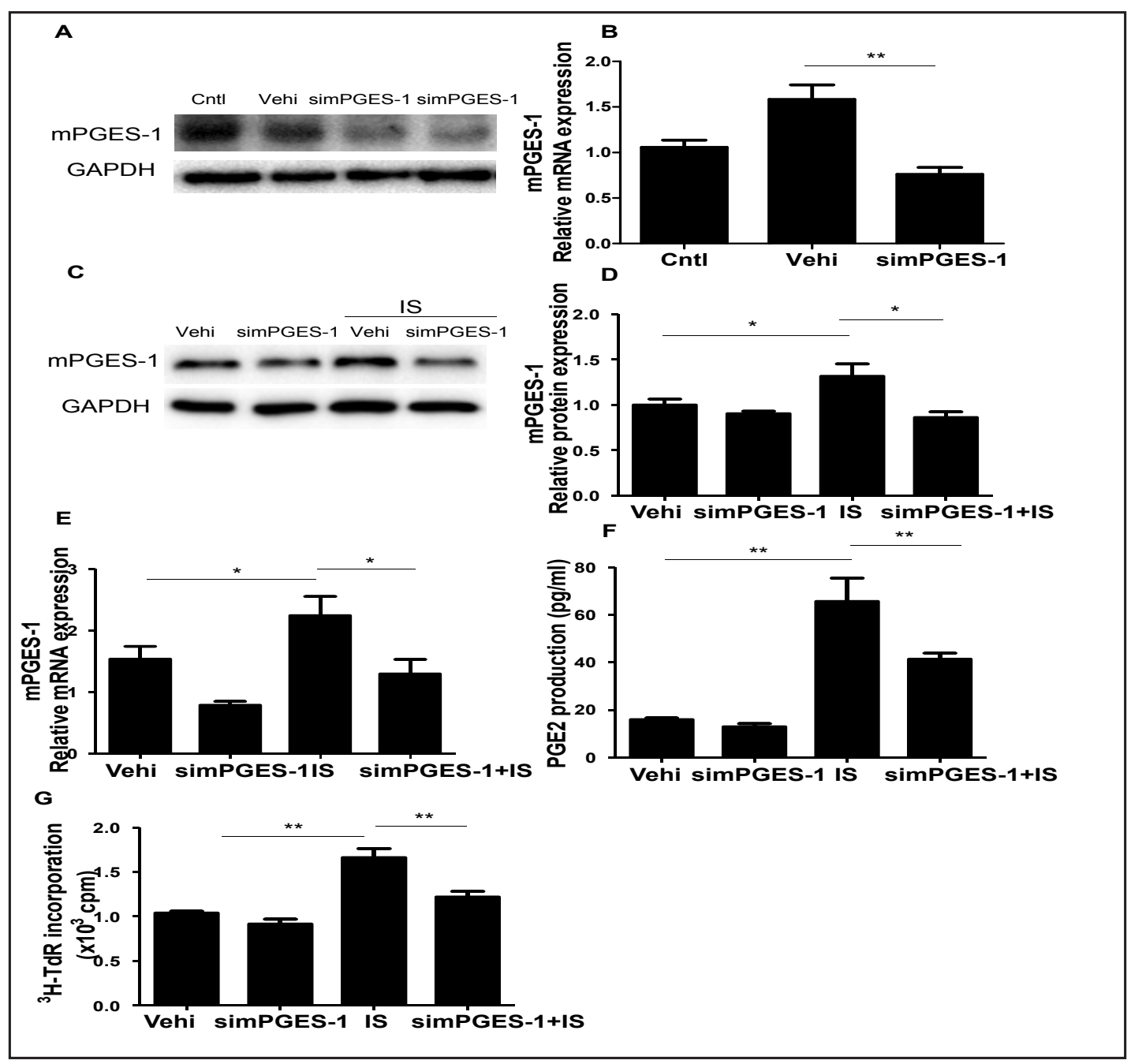

Fig. 2. Silencing mPGES-1 via a siRNA approach ameliorated IS-induced increments of MC number and PGE production. To examine the role of mPGES-1 in IS-induced cell cycle progression, mPGES-1 siRNA was applied to MCs. (A) Protein levels of mPGES-1 in MCs with mPGES-1 siRNA or negative control treatment. (B) mRNA levels of mPGES-1 in MCs with mPGES-1 siRNA or negative control treatment. (C) Representative images of Western blots of mPGES-1 with or without mPGES-1 silencing in response to IS treatment. (D) Quantitative analysis of Western blots in C. (E) qRT-PCR analysis of mPGES-1. (F) EIA assay of PGE ${ }_{2}$ in medium. (G) The assay of $\left[{ }^{3} \mathrm{H}\right]$ thymidine incorporated into the newly synthesized DNA after IS treatment with or without mPGES-1 silencing. All values are means $\pm \mathrm{SD} ; \mathrm{n}=6$ in each group. ${ }^{*} \mathrm{P}<0.05$ vs. control or IS group, ** $\mathrm{P}<0.01$ vs. control or IS group.

\section{KARGER}


Fig. 3. Silencing $\mathrm{mPG}$ ES-1 blunted IS-induced cell cycle progression in MCs. (A-D) Representative images of cell cycle following mPGES-1 siRNA transfection with or without IS treatment. (E-H) Percentage of cells at G1/G0 (E), G2/M (F), $S(G)$, and $(S+G 2) / M$ (H) phases following mPGES-1 siRNA transfection with or without IS treatment. All values are means $\pm S D ; n=6$ in each group. ${ }^{*} \mathrm{P}<0.05$ vs. control or IS group, ** $\mathrm{P}<0.01$ vs. control or IS group.

Fig. 4. Silencing $\mathrm{mPG}$ ES-1 blocked IS-induced upregulation of cyclins in MCs. The cells were transfected with mPGES-1 siRNA for $24 \mathrm{~h}$ before IS (500 $\mu \mathrm{M})$ administration. (A \& B) qRTPCR analysis of cyclin A2 (A) and cyclin D1 (B). (C) Representative images of Western blots of cyclin A2 and cyclin D1. (D) Quantitative analysis of Western blots in C. All values are means \pm SD; $n=6$ in each group. $* \mathrm{P}<0.05$ vs. control or IS group, ${ }^{* *} \mathrm{P}<0.01$ vs. control or IS group.
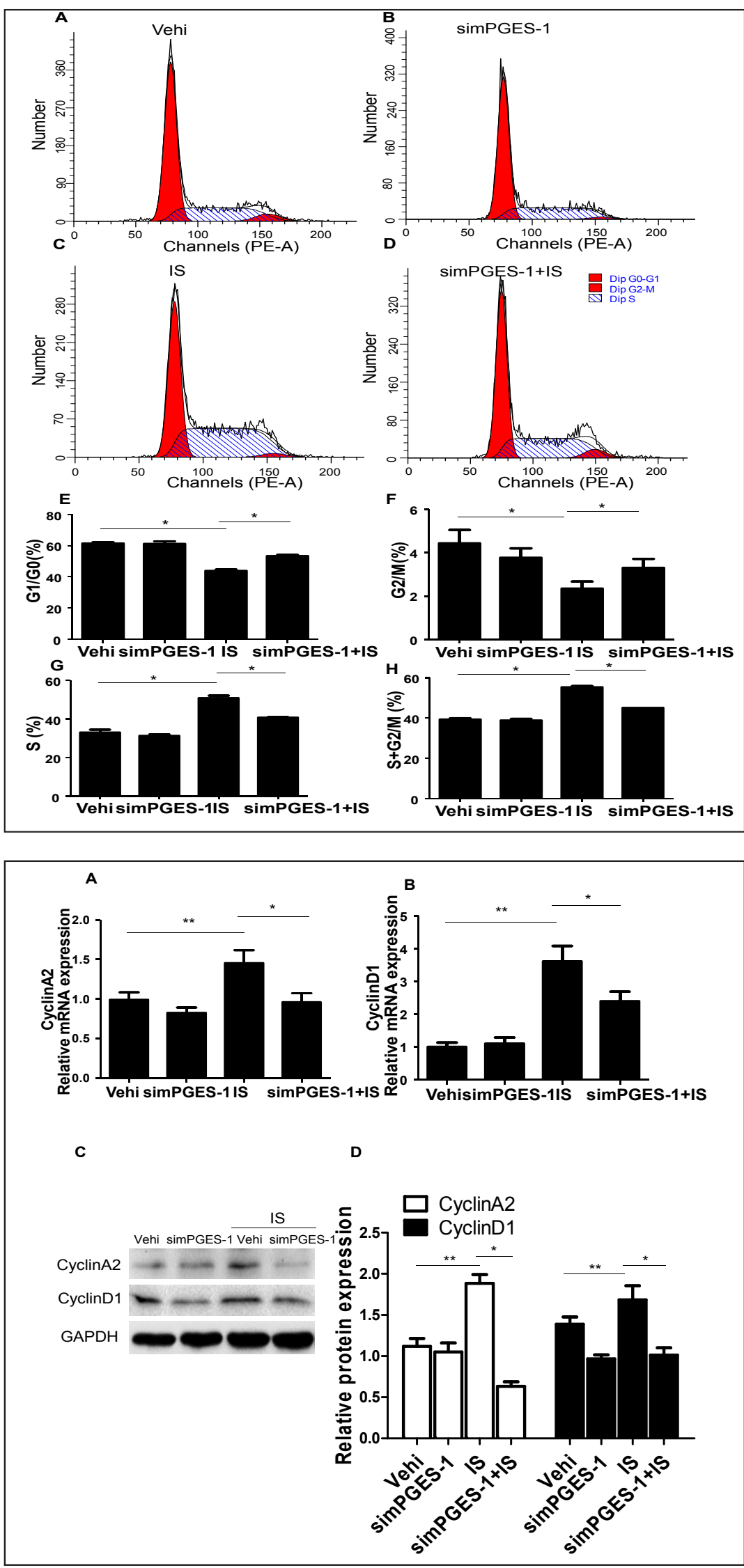
Fig. 5. Effect of $\mathrm{PGE}_{2}$ on cell cycle progression in MCs. MCs were treated with $\mathrm{PGE}_{2}$ at different concentrations $(5,10,100 \mathrm{nM})$ for $24 \mathrm{~h}$ before analyzing the cell cycle progression. (A-D) Representative images of cell cycle following $\mathrm{PGE}_{2}$ treatment. (E-H) Percentage of cells at G1/ G0 (E), G2/M (F), S (G), and $(\mathrm{S}+\mathrm{G} 2) / \mathrm{M}(\mathrm{H})$ phases following $\mathrm{PGE}_{2}$ treatment. All values are means $\pm \mathrm{SD} ; \mathrm{n}=$ 6 in each group; ${ }^{*} \mathrm{P}<0.05$ vs. control, $* * \quad \mathrm{P}<0.01$ vs. control.

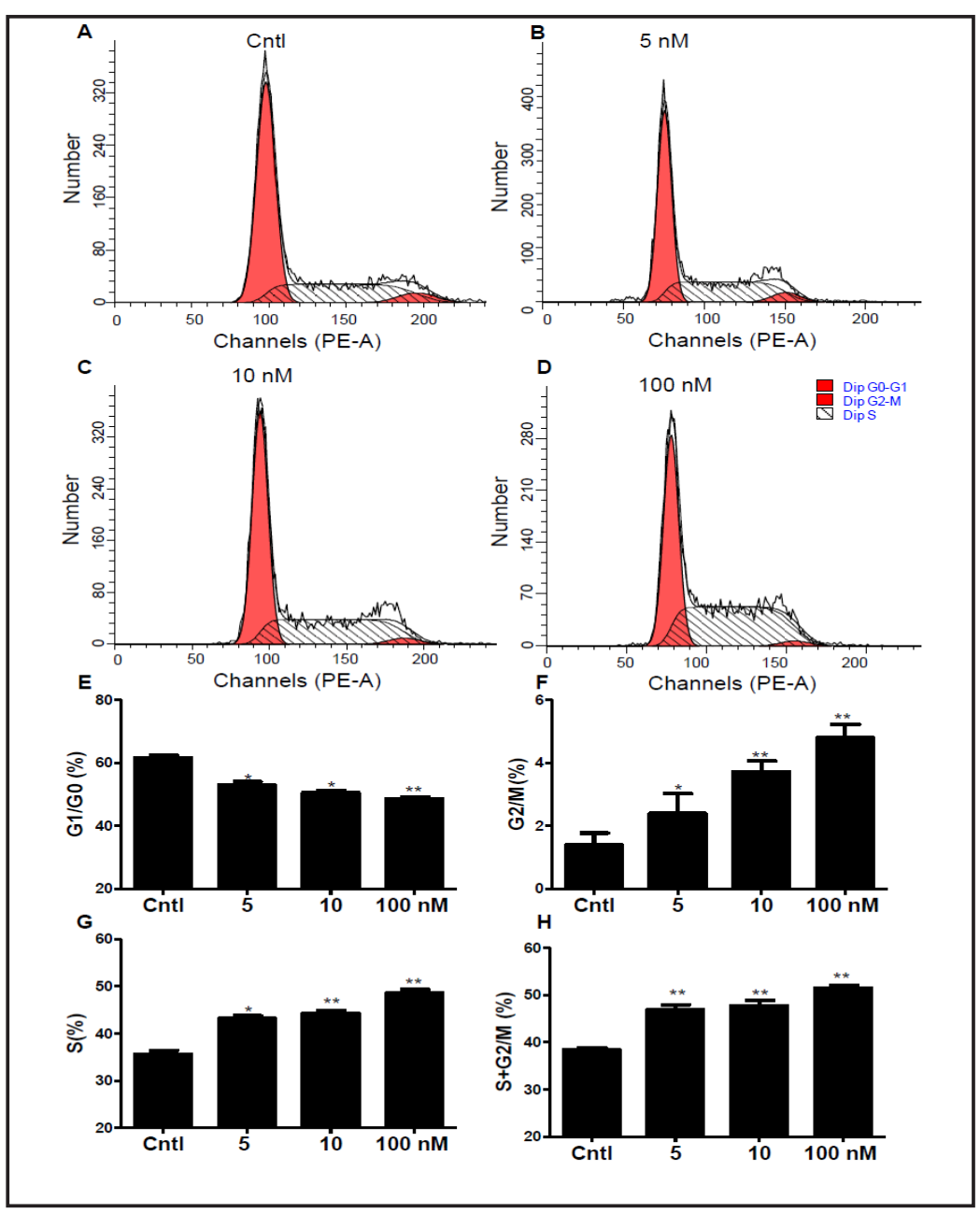

\section{$P G E_{2}$ induced $M C$ proliferation}

To evaluate the direct role of $\mathrm{PGE}_{2}$ in modulating cell cycle progression, we treated the MCs with $\mathrm{PGE}_{2}$ As expected, exogenous $\mathrm{PGE}_{2}$ increased $\mathrm{MC}$ cell population in $\mathrm{S}$ phase and decreased the percentage of cells in G1/G0 phase(Fig.5A-H), suggesting that PGE $_{2}$ could directly trigger cell cycle progression in MCs. Furthermore, we examined the effect of $\mathrm{PGE}_{2}$ on the expressions of cyclin D1 and cyclin A2. By the analyses of qRT-PCR and Western blotting, we observed that $\mathrm{PGE}_{2}$ significantly increased the expressions of cyclin D1 and cyclin A2 in a dose-dependent manner (Fig.6A-E). Consistently, the assay of $\left[{ }^{3} \mathrm{H}\right]$ thymidine indicated that the synthesis of DNA was also increased by $\mathrm{PGE}_{2}$ treatment (Fig. 6F). These results indicated a direct role of $\mathrm{PGE}_{2}$ in promoting $\mathrm{MC}$ proliferation.

\section{$P G E_{2}$ treatment selectively upregulated EP2 expression}

To identify the potentially involved EP(s) in mediating $\mathrm{PGE}_{2}$ effect on $\mathrm{MC}$ proliferation,

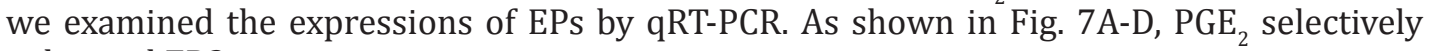
enhanced EP2 expression.

\section{IS treatment stimulated NF- $\kappa B$ phosphorylation}

Activation of NF- $\kappa B$ signaling has a known role in many diseases including chronic kidney diseases (CKDs). Thus, we examined the phosphorylation of NF- $\kappa \mathrm{B}$ and observed that IS stimulated NF- $\mathrm{BB}$ phosphorylation in MCs (Fig. 7E and F), suggesting an involvement of

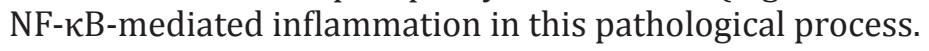


Fig. 6. Effects of $\mathrm{PGE}_{2}$ on the expressions of cyclin D1 and cyclin A2 in MCs. (A \& B) After MCs were treated with $\mathrm{PGE}_{2}$ $(5,10,100 \mathrm{nM})$ for 24 $h$, the mRNA levels of of cyclin A2 (A) and cyclin D1 (B) were examined. (C) Representative images of Western blots of cyclin A2 and cyclin D1. (D) Quantitative analysis of Western blots of cyclinA2. (E) Quantitative analysis of Western blots of cyclin D1. (F) The assay of $\left[{ }^{3} \mathrm{H}\right]$ thymidine incorporated into the newly synthesized DNA of MCs with or without $\mathrm{PGE}_{2}$ treatment. All values are means \pm $\mathrm{SD} ; \mathrm{n}=6$ in each group; $* \mathrm{P}<0.05$ vs. control, ** $\mathrm{P}<0.01$ vs. control.

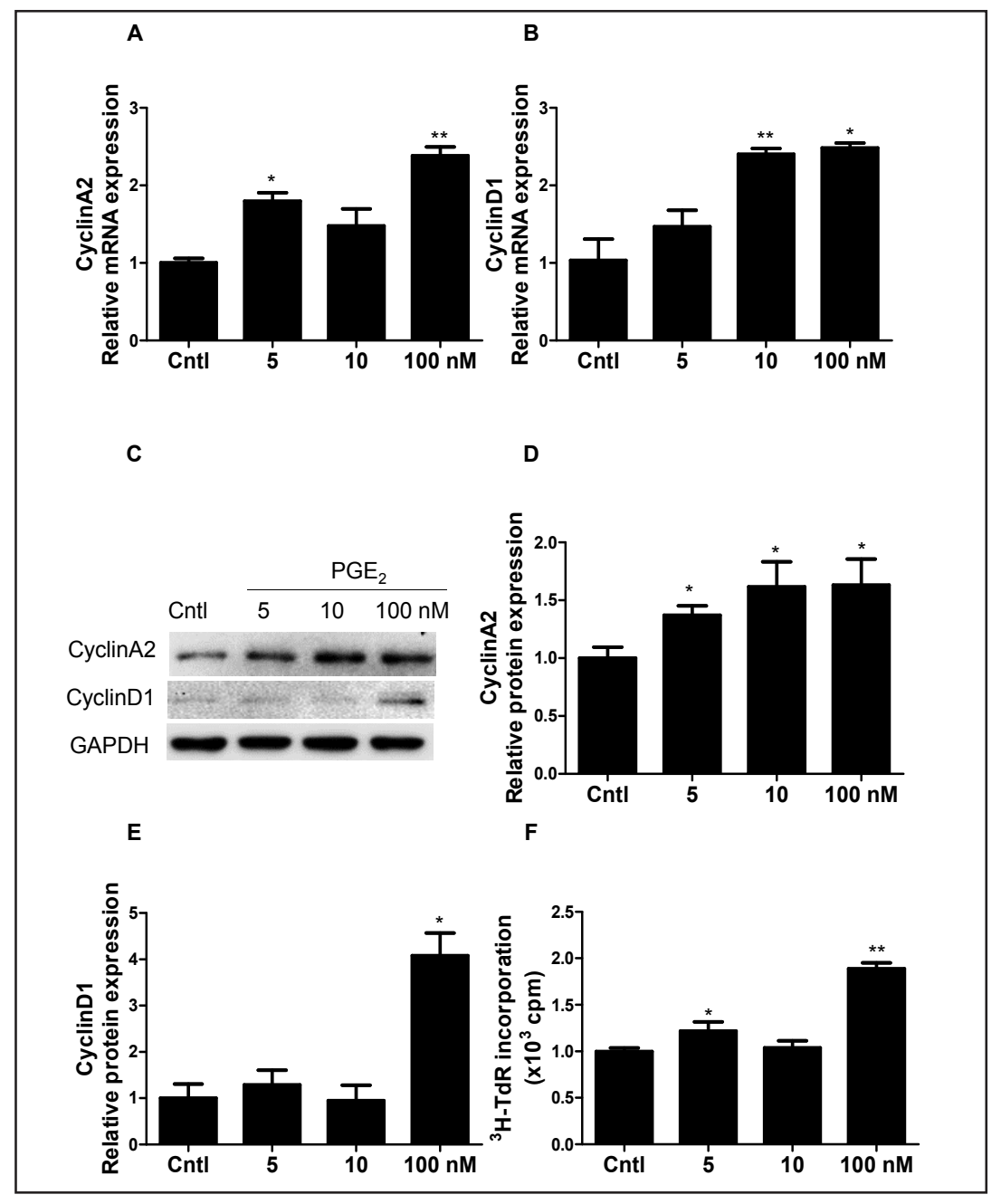

\section{Discussion}

In the clinical practice, preserving RKF in CKD patients is one of the major goals of nephrologists $[4,26,27]$. RKF is particularly important for maintaining a better status of health even in the patients with dialysis therapy [28-30]. RKF not only benefits the urinary excretion of salt and water, but also helps to remove the large molecular uremic toxins which can't be effectively cleared by dialysis $[2,4,5]$. As one of the well-known proteinbound uremic toxins [31], IS is markedly accumulated in the circulation of patients with advanced CKDs $[6,32,33]$. In this study, we reported that IS stimulated MC proliferation through mPGES-1/PGE2 cascade, which may contribute to the progressive loss of RKF to some extent.

The cell cycle is a set of events responsible for the duplication of cells. Its fundamental task is to ensure the faithful DNA replication and identical chromosomal copy in daughter cells [34]. The progression of the cell cycle is controlled by cyclins which are synthesized at specific stages of the cell cycle. The synthesis of cyclin D is initiated during G1 and drives the G1/S phase transition [35], and cyclin A-associated kinase activity is required for the entry into S phase, completion of S phase, as well as the entry into M phase [36]. Thus, the expressions of cyclin D1 and cyclin A2 were generally used as the markers for cell cycle progression. Here we showed IS significantly induced cyclin A2 and cyclin D1 expression in MCs in parallel with increased cell percentage in S phase. These findings suggest that IS serves as a potent contributor of cell cycle progression and cell proliferation in MCs.

\section{KARGER}


Fig. 7. The expressions of EP1-4 and $\mathrm{p}-\mathrm{NF}-\kappa \mathrm{B}$ in MCs following $\mathrm{PGE}_{2}$ or IS treatment. After MCs were treated with $\mathrm{PGE}_{2}$ at different doses, EP1 (A), EP2 (B), EP3 (C) and EP4 (D) were examined via qRT-PCR. (E) Representative image of Western blots of p-NF-кB. MCs were treated with IS at a dose of $500 \mu \mathrm{M}$ at indicated time points. (F) Quantitative analysis of Western blots of $\mathrm{p}-\mathrm{NF}-\kappa \mathrm{B}$. All values are means $\pm \mathrm{SD}$; $\mathrm{n}=6$ in each group. * $\mathrm{P}<0.05$ vs. control, $* *$ $\mathrm{P}<0.01$ vs. control.

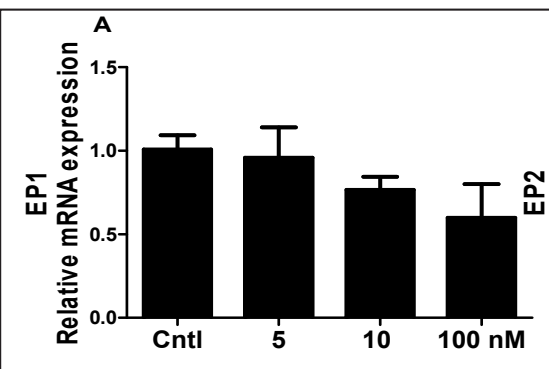

c
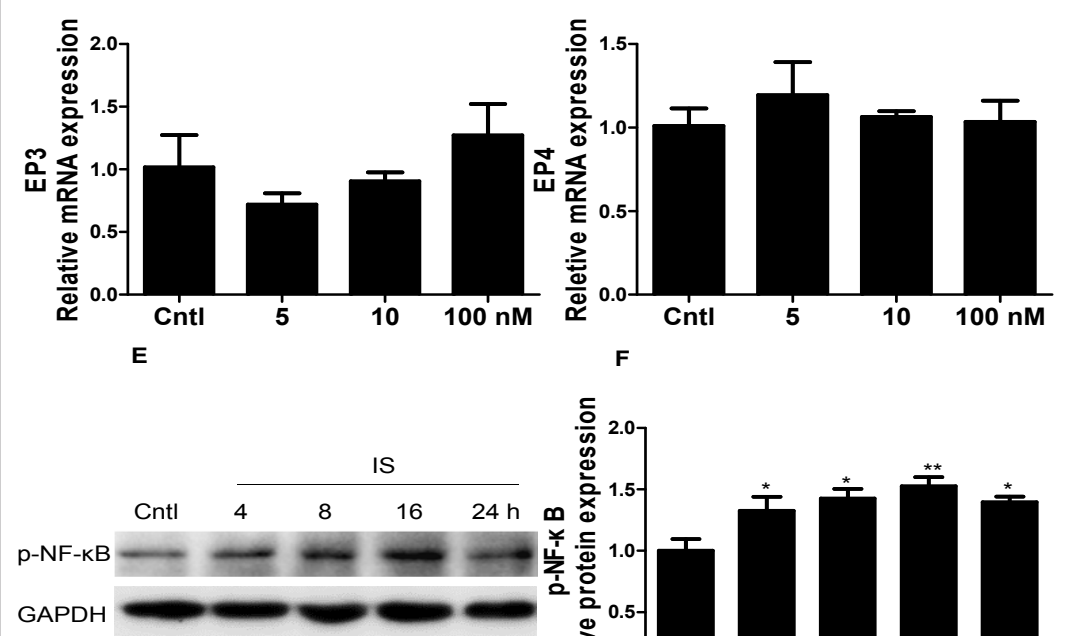

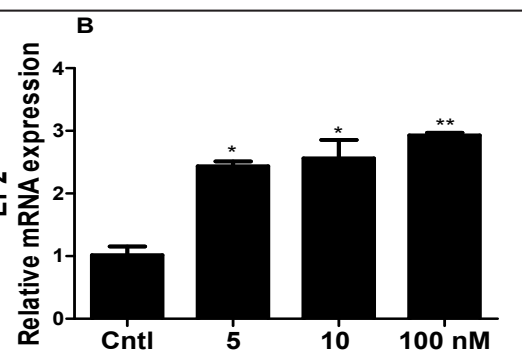

D

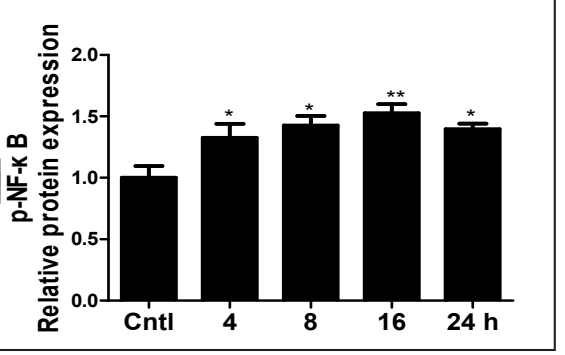

In our previous study, we reported that IS significantly promoted cell cycle progression via upregulating COX-2 expression in mesangial cells [13]. However, whether mPGES-1/PGE (a downstream cascade of COX-2) plays a role in mediating COX-2 effect on MC proliferation is still unknown. Here we examined the regulation of mPGES-1 in IS-treated MCs and found that mPGES-1 was significantly induced by IS, suggesting a potential involvement of mPGES-1 in mediating IS-induced MC proliferation. At the same time, we found that the expression of mPGES-2 was significantly downregulated by IS in line with a trend reduction of cPGES. To our knowledge, although the in vitro evidence suggested that mPGES-2 and PGES could contribute to the baseline $\mathrm{PGE}_{2}$ production [37], genetic deletion of mPGES-2 or cPGES in mice did not reduce $\mathrm{PGE}_{2}$ levels in different organs [38-40], which strongly argues against the nature of these two enzymes as the $\mathrm{PGE}_{2}$ synthases.

Next, we explored the functional role of mPGES-1 in mesangial cell proliferation induced by IS using mPGES-1 siRNA. Similar as COX-2 inhibition [13], mPGES-1 silencing inhibited IS-induced MC proliferation as evidenced by the blocked cell cycle progression and reduced cell number. Meanwhile, the $\mathrm{PGE}_{2}$ production induced by IS was also blunted. These data suggested that mPGES-1-derived $\mathrm{PGE}_{2}$ contributed to the mesangial cell proliferation. To further verify this conclusion, we treated mesangial cells with exogenous $\mathrm{PGE}_{2}$ and observed a direct effect of $\mathrm{PGE}_{2}$ on inducing mesangial cell proliferation.

Furthermore, we examined the potentially involved $\mathrm{PGE}_{2}$ receptors mediating $\mathrm{PGE}_{2}$ effect on MC proliferation. Following PGE $\mathrm{E}_{2}$ treatment, we found a selective upregulation of EP2 but not other EPs, which suggests that EP2 might be the potential receptor mediating the $\mathrm{PGE}_{2}$ effect on MC proliferation. Finally, we found that IS induced the phosphorylation of NF$\kappa \mathrm{B}$, indicating that NF- $\kappa \mathrm{B}$-mediated inflammation might be also involved in this pathological process.

In summary, in the present study, we demonstrated a pathogenic role of mPGES-1-derived $\mathrm{PGE}_{2}$ in IS-induced MC proliferation possibly through EP2 receptor. Currently, mPGES-1 is a

\section{KARGER}




\section{Cellular Physiology Cell Physiol Biochem 2017;43:271-281

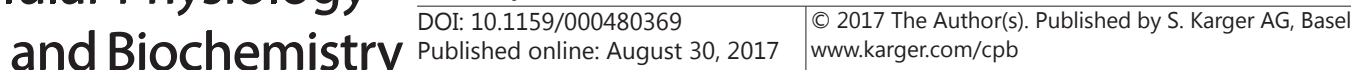

Li et al.: mPGES-1-Derived PGE ${ }_{2}$ and is-Induced Mesangial Cell Proliferation

hot target for the development of new anti-inflammatory drugs. The findings from current study suggest that inhibition of mPGES- 1 might potentially serve as a therapeutic strategy in protecting against the uremic toxin-related glomerular damage and RKF loss in advanced CKDs.

\section{Acknowledgements}

This work was supported by Grants from the National Natural Science Foundation of China (nos. 81370802, 81300591, 81670647, 81600557, 81600352, 81600532 and 81570616), the National Key Research and Development Program (no. 2016YFC0906103), the Natural Science Foundation of Jiangsu Province (no. BK2012001, BK20160137, and BK20160136), Projects of Jiangsu Province Science and Education Qiang Wei (no. QNRC2016091 and ZDRCA2016074), and Project of Nanjing National Commission on Health and Family Planning (no. ZKX16059 and ZKX16057).

\section{Disclosure Statement}

There is no Disclosure Statement to disclose.

\section{References}

1 Hemodialysis Adequacy Work G: Clinical practice guidelines for hemodialysis adequacy, update 2006. Am J Kidney Dis 2006;48:S2-90.

- Marquez IO, Tambra S, Luo FY, Li Y, Plummer NS, Hostetter TH, Meyer TW: Contribution of residual function to removal of protein-bound solutes in hemodialysis. Clin J Am Soc Nephr 2011;6:290-296.

3 Wang AY, Lai KN: The importance of residual renal function in dialysis patients. Kidney Int 2006;69:17261732.

4 Bargman JM, Thorpe KE, Churchill DN, Group CPDS: Relative contribution of residual renal function and peritoneal clearance to adequacy of dialysis: a reanalysis of the CANUSA study. J Am Soc Nephrol 2001;12:2158-2162.

5 Paniagua R, Amato D, Vonesh E, Correa-Rotter R, Ramos A, Moran J, Mujais S, Mexican Nephrology Collaborative Study G: Effects of increased peritoneal clearances on mortality rates in peritoneal dialysis: ADEMEX, a prospective, randomized, controlled trial. J Am Soc Nephrol 2002;13:1307-1320.

6 Tan X, Cao X, Zou J, Shen B, Zhang X, Liu Z, Lv W, Teng J, Ding X: Indoxyl sulfate, a valuable biomaker in chronic kidney disease and dialysis. Hemodial Int 2017;21:161-167.

7 Niwa T, Takeda N, Tatematsu A, Maeda K: Accumulation of indoxyl sulfate, an inhibitor of drug-binding, in uremic serum as demonstrated by internal-surface reversed-phase liquid chromatography. Clin Chem 1988;34:2264-2267.

8 Niwa T, Ise M: Indoxyl sulfate, a circulating uremic toxin, stimulates the progression of glomerular sclerosis. J Lab Clin Med 1994;124:96-104.

-9 Niwa T, Yazawa T, Ise M, Sugano M, Kodama T, Uehara Y, Maeda K: Inhibitory effect of oral sorbent on accumulation of albumin-bound indoxyl sulfate in serum of experimental uremic rats. Nephron 1991;57:84-88.

10 Niwa T, Emoto Y, Maeda K, Uehara Y, Yamada N, Shibata M: Oral sorbent suppresses accumulation of albumin-bound indoxyl sulphate in serum of haemodialysis patients. Nephrol Dial Transplant 1991;6:105109.

11 Pham NM, Recht NS, Hostetter TH, Meyer TW: Removal of the protein-bound solutes indican and p-cresol sulfate by peritoneal dialysis. Clin J Am Soc Nephrol 2008;3:85-90.

12 Floege J, Eng E, Young BA, Johnson RJ: Factors involved in the regulation of mesangial cell proliferation in vitro and in vivo. Kidney Int 1993;39:S47-54.

13 Huang NQ Jin H, Zhou SY, Shi JS, Jin F: TLR4 is a link between diabetes and Alzheimer's disease. Behav Brain Res 2017;316:234-244.

14 Imaizumi T, Yano C, Numata A, Tsugawa K, Hayakari R, Matsumiya T, Yoshida H, Watanabe S, Tsuruga K, Kawaguchi S, Murakami M, Tanaka H: Interferon (IFN)-Induced Protein 35 (IFI35), a Type I InterferonDependent Transcript, Upregulates Inflammatory Signaling Pathways by Activating Toll-Like Receptor 3 in 


\section{Cellular Physiology Cell Physiol Biochem 2017;43:271-281 \begin{tabular}{l|l|l} 
and Biochemistry Publisned onlIne: August 30, 2017 & $\begin{array}{l}\text { (c) } 2017 \text { The Author(s). Published by S. Karger AG, Basel } \\
\text { www.karger.com/cpb }\end{array}$
\end{tabular}}

Human Mesangial Cells. Kidney Blood Press Res 2016;41:635-642.

15 Yang M, Wang B, Miao L, Xu X, He X: Autophagy is involved in aldosteroneinduced mesangial cell proliferation. Mol Med Rep 2016; 14:4638-4642.

-16 Zhang L, Kong D, Meng H, Han C, Zhu J, Qiao J, He Y, Wang T, Li X, Zhang F, Jin X: Plasma Gelsolin Promotes Proliferation of Mesangial Cell in IgA Nephropathy. Cell Physiol Biochem 2016;40:1473-1486.

$>17$ Zhang A, Han Y, Wang B, Li S, Gan W: Beyond Gap Junction Channel Function: the Expression of Cx43 Contributes to Aldosterone-Induced Mesangial Cell Proliferation via the ERK1/2 and PKC Pathways. Cell Physiol Biochem 2015;36:1210-1222.

18 Wang D, Guan MP, Zheng ZJ, Li WQ Lyv FP, Pang RY, Xue YM: Transcription Factor Egr1 is Involved in High Glucose-Induced Proliferation and Fibrosis in Rat Glomerular Mesangial Cells. Cell Physiol Biochem 2015;36:2093-2107.

19 Liang Y, Zhang J, Zhou Y, Xing G, Zhao G, Liu Z: Proliferation and Cytokine Production of Human Mesangial Cells Stimulated by Secretory IgA Isolated from Patients with IgA Nephropathy. Cell Physiol Biochem 2015;36:1793-1808.

20 Kong F, Ma L, Zou L, Meng K, Ji T, Zhang L, Zhang R, Jiao J: Alpha1-Adrenergic Receptor Activation Stimulates Calcium Entry and Proliferation via TRPC6 Channels in Cultured Human Mesangial Cells. Cell Physiol Biochem 2015;36:1928-1938.

21 Rodriguez-Iturbe B, Garcia Garcia G: The role of tubulointerstitial inflammation in the progression of chronic renal failure. Nephron Clin Pract 2010;116:c81-88.

22 Paul AG, Chandran B, Sharma-Walia N: Cyclooxygenase-2-prostaglandin E2-eicosanoid receptor inflammatory axis: a key player in Kaposi's sarcoma-associated herpes virus associated malignancies. Transl Res 2013;162:77-92.

23 Jia Z, Wang H, Yang T: Microsomal prostaglandin E synthase 1 deletion retards renal disease progression but exacerbates anemia in mice with renal mass reduction. Hypertension 2012;59:122-128.

-24 Jia Z, Wang N, Aoyagi T, Wang H, Liu H, Yang T: Amelioration of cisplatin nephrotoxicity by genetic or pharmacologic blockade of prostaglandin synthesis. Kidney Int 2011;79:77-88.

25 Pozarowski P, Darzynkiewicz Z: Analysis of cell cycle by flow cytometry. Methods Mol Biol 2004;281:301311.

26 Szeto CC, Wong TY, Leung CB, Wang AY, Law MC, Lui SF, Li PK: Importance of dialysis adequacy in mortality and morbidity of chinese CAPD patients. Kidney Int 2000;58:400-407.

27 Tam P: Peritoneal dialysis and preservation of residual renal function. Perit Dial Int 2009;29:S108-110.

-28 Rumpsfeld M, McDonald SP, Johnson DW: Peritoneal small solute clearance is nonlinearly related to patient survival in the Australian and New Zealand peritoneal dialysis patient populations. Perit Dial Int 2009;29:637-646.

29 Harty J, Gokal R: The impact of peritoneal permeability and residual renal function on PD prescription. Perit Dial Int 1996;16:S147-152.

-30 Yan MT, Cheng CJ, Wang HY, Yang CS, Peng SJ, Lin SH: Evaluating Hyponatremia in Non-Diabetic Uremic Patients on Peritoneal Dialysis. Perit Dial Int 2016;36:196-204.

-31 Brunet P, Dou L, Cerini C, Berland Y: Protein-bound uremic retention solutes. Adv Ren Replace Ther 2003;10:310-320.

32 Niwa T: Uremic toxicity of indoxyl sulfate. Nagoya J Med Sci 2010;72:1-11.

33 Niwa T: Indoxyl sulfate is a nephro-vascular toxin. J Ren Nutr 2010;20:S2-6.

34 Heichman KA, Roberts JM: Rules to replicate by. Cell 1994;79:557-562.

-35 Pardo FS, Su M, Borek C: Cyclin D1 induced apoptosis maintains the integrity of the G1/S checkpoint following ionizing radiation irradiation. Somat Cell Mol Genet 1996;22:135-144.

-36 Girard F, Strausfeld U, Fernandez A, Lamb NJ: Cyclin A is required for the onset of DNA replication in mammalian fibroblasts. Cell 1991;67:1169-1179.

-37 Yang T: Microsomal prostaglandin E synthase-1 and blood pressure regulation. Kidney Int 2007;72:274278.

38 Lovgren AK, Kovarova M, Koller BH: cPGES/p23 is required for glucocorticoid receptor function and embryonic growth but not prostaglandin E2 synthesis. Mol Cell Biol 2007;27:4416-4430.

-39 Nakatani Y, Hokonohara Y, Kakuta S, Sudo K, Iwakura Y, Kudo I: Knockout mice lacking cPGES/p23, a constitutively expressed PGE2 synthetic enzyme, are peri-natally lethal. Biochem Biophys Res Commun 2007;362:387-392.

-40 Sun Y, Jia Z, Yang G, Kakizoe Y, Liu M, Yang KT, Liu Y, Yang B, Yang T: mPGES-2 deletion remarkably enhances liver injury in streptozotocin-treated mice via induction of GLUT2. J Hepatol 2014;61:1328-1336. 